\title{
A pandemia e a urgência das tecnologias: reflexões sobre os desafios para o ensino de língua portuguesa em tempos de isolamento social
}

\author{
The pandemic and the urgency of technologies: reflection on the challenges for teaching Portuguese in times \\ of social isolation
}

Wellington Gomes de Souza

Universidade do Estado do Rio Grande do Norte - UERN - Rio Grande do Norte - Brasil

Jaqueline de Jesus Bezerra

Universidade do Estado do Rio Grande do Norte - UERN - Rio Grande do Norte - Brasil

\begin{abstract}
Resumo: A construção de espaços de aprendizagem que sejam baseados no uso das tecnologias digitais de informação e comunicação (TDIC) tornou-se algo extremamente necessário neste contexto adverso no qual se encontra a educação, em função da pandemia causada pelo novo coronavírus. Dessa forma, este artigo tem como objetivo discutir os desafios evidenciados com o isolamento social, no tocante à transformação da atividade docente com base no uso de tecnologias para o ensino de língua portuguesa. Assim, o objeto de estudo almejado passa pela análise dos recursos tecnológicos utilizados pelo professor, pela metodologia empregada e pela relação com os discentes no tratamento didático dos conteúdos. Para fundamentar esta abordagem, pautou-se nas discussões propostas por Braga (2013), Zacharias (2016), Rojo (2012), além da consideração de aspectos empíricos inerentes ao cenário analisado. A pesquisa é de abordagem quantitativa, subsidiada por levantamento bibliográfico e tem objetivo descritivo-explicativo, centrada na análise das respostas de cinquenta e cinco professores de uma regional da rede estadual do Ceará, sobre questões concernentes a esse momento de ensino remoto. Diante da análise proposta, entende-se que o cenário desafiante para o ensino de língua portuguesa, por meio de TDIC, torna-se mais evidente nesse contexto pandêmico de isolamento social. Da mesma forma, constatase que há lacunas relativas ao uso do aparato tecnológico em prol da aprendizagem, algo que converge para o pensamento acerca do fortalecimento do processo formativo docente nessa perspectiva.
\end{abstract}

Palavras-chave: Língua Portuguesa. Ensino. Tecnologias. Isolamento social. Desafios.

Abstract The construction of learning spaces that are based on the use of digital information and communication technologies (TDIC) has become something extremely necessary in this adverse context in which education is found, due to the pandemic caused by the new coronavirus. Thus, this article aims to discuss the challenges highlighted by social isolation, with regard to the transformation of teaching activity based on the use of technologies for teaching Portuguese. Thus, the object of study sought is the analysis of technological resources used by the teacher, the methodology used and the relationship with students in the didactic treatment of the contents. To support this approach, it was based on the discussions proposed by Braga (2013), Zacharias (2016), Rojo (2012), besides the consideration of empirical aspects inherent to the analyzed scenario. The research has a quantitative approach, supported by a bibliographic survey and has a descriptive-explanatory objective, centered on the analysis of the responses of fifty-five teachers from a regional school in the state of Ceará, on issues concerning this moment of remote teaching. In view of the proposed analysis, it is understood that the challenging scenario for the teaching of the Portuguese language, through TDIC, becomes more evident in this pandemic context of social isolation. In the same way, it appears that there are gaps related to the use of the technological apparatus in favor of learning, something that converges to the thinking about the strengthening of the teacher training process in this perspective.

Keywords: Portuguese language. Teaching. Technologies. Social isolation. Challenges. 


\section{Introdução}

A pandemia provocada pela disseminação do novo coronavírus obrigou os diversos setores da sociedade a adequarem-se ao novo contexto social, marcado pelo isolamento. No contexto escolar, a suspensão das aulas fez com que os atores educacionais buscassem novos caminhos para a criação de situações de aprendizagem que fossem eficazes, considerando o ensino remoto.

Com essa situação, evidenciam-se as dificuldades relativas ao ensino a distância e ao uso da tecnologia, pois alunos, professores, gestores e demais membros da comunidade escolar não possuem, de modo geral, aptidões para a utilização de recursos tecnológicos em prol do ensino, além de não haver autonomia dos discentes para estudarem em casa, entre outras situações complexas a respeito dessa temática.

Dessa forma, este artigo tem como objetivo discutir os desafios evidenciados pelo isolamento social, no tocante à transformação da atividade docente com base no uso de tecnologias para o ensino de língua portuguesa. Com esse escopo de análise, trataremos do uso de dispositivos tecnológicos na perspectiva do ensino como um todo e direcionaremos as observações para a abordagem dos conteúdos de português, considerando os recursos utilizados pelos professores, o tratamento didático dos conteúdos da disciplina e a atuação dos discentes nessa perspectiva de atendimento. Para tanto enviamos um questionário para cinquenta e cinco professores língua portuguesa da rede estadual de educação do Ceará, lotados em turmas de ensino médio com esta disciplina.

A discussão proposta perpassa por autores como Rojo (2012), Braga (2013) Almeida (2014), entre outros estudiosos que tratam da agenda de uso das tecnologias digitais de informação e comunicação, do desenvolvimento de práticas (multi) letradas no âmbito escolar e do trabalho com textos, a partir da utilização de dispositivos tecnológicos. Da mesma forma, baseamo-nos na experiência acerca das particularidades referentes ao uso de tecnologias no contexto escolar, tendo em vista 0 nosso conhecimento, como professores, em relação a esse tipo de prática pedagógica.

Fundamentamos

a pesquisa, metodologicamente, à luz de Prodanov e Freitas (2013). Assim, categorizamos a investigação, do ponto de vista do procedimento técnico, como levantamento, considerando que nesse tipo de pesquisa, há interrogação de pessoas, através de questionário, a fim de se conhecer alguma realidade específica, neste caso, a experiência do ensino remoto em tempos de isolamento social. Além disso, fomenta-se uma abordagem quantitativa, realizando-se a quantificação dos dados obtidos a fim de que contribuam para se chegar a conclusões. Ademais, a pesquisa tem objetivo descritivo-explicativo, pois descreve os dados coletados a partir do questionário aplicado e explica esses dados, com vistas a mostrar, ainda que em linhas gerais, a visão dos professores acerca do processo de ensino remoto em consequência do isolamento provocado pela pandemia.

Como resultados dessa discussão, podemos citar o fato de que o uso da tecnologia nesse contexto de ensino está atrelado a práticas pedagógicas tradicionais, como ocorre com a orientação de atividades do livro didático. Além disso, evidenciam-se as desigualdades sociais entre alunos, sobretudo com a impossibilidade de acesso à internet, uma das maiores dificuldades dos estudantes em relação ao atendimento remoto. Dessa forma, observamos, entre outros aspectos, lacunas no tocante a formação docente para o uso pleno da tecnologia, algo que deve ser fortalecido nestes tempos pandêmicos.

Nas seções que seguem, discutiremos sobre as tecnologias na perspectiva do ensino, fazendo uma abordagem geral sobre as práticas multiletradas e discutindo, brevemente, sobre a possibilidade de criação de webcurrículos na escola, em uma perspectiva integrativa entre TDIC e os multiletramentos. Posteriormente, trataremos do trabalho com língua portuguesa na perspectiva dos multiletramentos e com o uso de tecnologias no contexto escolar. Na seção derradeira, apontaremos algumas questões desafiadoras para o ensino em tempos de isolamento social e apresentaremos uma 
breve análise do questionário aplicado para professores de língua portuguesa, tomando como base as práticas pedagógicas no ensino remoto. Finalizando o artigo, faremos nossas considerações acerca da problemática levantada.

\section{As tecnologias na perspectiva do ensino:} uma abordagem geral sobre práticas multiletradas e a construção de webcurrículos

A inserção de práticas de ensino pautadas na tecnologia permite aos professores uma caminhada pedagógica para além dos limites do livro didático. Partindo desse mote, é de grande valia a discussão sobre os novos letramentos que são possibilitados a partir do uso de recursos digitais, tendo em vista a necessidade de aproximação entre as situações de aprendizagem e os contextos sociais dos quais fazem parte os discentes. Nessa perspectiva, podem ser construídos mecanismos de estreitamento para essa relação entre ensino e contexto social, mediante o uso de recursos tecnológicos.

Esses novos letramentos, que perpassam diversas áreas de conhecimento, estão relacionados ao uso da internet e às possibilidades que ela oferece para as mudanças do comportamento comunicativo dos indivíduos, com a perspectiva de incorporação de semioses que vão além da utilização de recursos verbais, algo que transpõe a barreira da abordagem linguística e adentra em outras práticas sociais (MARCUSCHI, 2010).

Dessa maneira, as múltiplas semioses que são aventadas pelo uso das tecnologias constituem uma miríade de possibilidades para o processo de ensino-aprendizagem, tanto para o ensino de língua portuguesa - como observaremos na seção seguinte - como para outras disciplinas, tendo em vista que os recursos digitais que permeiam essas semioses oferecem subsídios pedagógicos para diferentes áreas acadêmicas, conforme aponta Braga (2013).

Nesse contexto multissemiótico, as novas possibilidades de abordagem pedagógica dos conteúdos são possíveis, de maneira geral, em função do advento das Tecnologias Digitais de Informação e
Comunicação (TDIC), reflexo das transformações tecnológicas que vêm contribuindo para as mudanças de perspectivas nos diversos setores da sociedade, inclusive no segmento educacional.

Nessa esteira de construção de conhecimentos a partir da tecnologia, os avanços nessa área têm permitido a reorganização logística das tarefas dos indivíduos. Assim, conforme aponta Braga (2013), as diversas práticas sociais podem ocorrer em distintos lugares, tendo em vista a dinamicidade proporcionada pelos vetores de informação, como celulares e notebooks, que permitem que qualquer lugar seja propício para o trabalho e para o estudo.

Com base nessas questões, pode-se dizer que, na perspectiva do ensino, a tecnologia permite que o tratamento dos conteúdos e as situações de aprendizagem sejam transpostos aos muros da escola. Pode-se acrescentar, também, que, em tempos de pandemia, como o que a sociedade está vivendo, torna-se mister o uso de todo aparato tecnológico em prol da aprendizagem. Por isso, é importante destacar que a tecnologia para o ensino no contexto vigente "[...] passa a ser uma demanda social e não uma mera 'opção' colocada para os indivíduos." (BRAGA, 2013, p. 40).

Ressaltemos, dessa forma, que a perspectiva demandada para o uso das TDIC em sociedade como um todo, também perpassando pelo contexto educacional, coaduna com a dimensão social de letramento, tendo em vista que esse fenômeno vai além da aquisição da tecnologia escrita (Cf. SOARES, 2014). Para estabelecer essa relação entre o uso das TDIC e a dimensão social do letramento, podemos observar que, na perspectiva das práticas letradas, há referência sobre a aquisição da escrita para o uso em práticas de linguagem diversas, sendo que o mero domínio de recursos para codificar e decodificar textos, por exemplo, consiste em uma dimensão individual de letramento, insuficiente para a participação efetiva em práticas sociais de linguagem e ineficaz para a construção do que Street (2014) chama de modelo ideológico de letramento.

Dessa forma, no tocante ao uso das TDIC, parece-nos que há um domínio das tecnologias no 
âmbito individual, tendo em vista que os sujeitos lidam com recursos tecnológicos diariamente, usando-os para determinados fins. Não obstante certo domínio para a utilização desses recursos, no caso dos atores do cenário educacional, isso não direciona para o êxito nas práticas de letramentos ou de multiletramentos necessárias no contexto vigente. Com base nisso, podemos dizer que os discentes, em sua maioria, dominam as tecnologias com vistas à finalidade lúdica, de entretenimento, muitas vezes, algo que não reflete em seu processo de aprendizagem. Isto é, a tecnologia não é posta a serviço educacional. Assim, talvez seja oportuno apontar para o fato de que as práticas (multi) letradas não refletem uma dimensão social ou ideológica de (multi)letramento, como se evidencia neste contexto pandêmico, por exemplo.

Em Rojo (2012), vemos a importância e a necessidade de uma pedagogia dos multiletramentos na escola, considerando a multiculturalidade que permeia a multiplicidade de linguagens e a constituição de multissemioses dos textos com os quais temos contato no contexto social. De acordo com a autora, a importância desse viés pedagógico está centrada na possibilidade de transformação das práticas de ensino e aprendizagem. Ainda assim, o uso da tecnologia no ambiente escolar ainda é posto, na maioria das vezes, em uma perspectiva proibitiva, conforme aponta a autora. Com isso, é possível dizer que essa construção social da tecnologia na escola dificulta a inserção de práticas educacionais sob esse parâmetro.

Outro ponto importante dessa discussão que estamos propondo diz respeito ao fato de que apesar de alunos e professores terem certo domínio da tecnologia e a usarem em determinados contextos sociais, isso não corresponde ao êxito no processo de ensino- aprendizagem, visto que as práticas sociais de uso dos recursos tecnológicos são distintas. Por isso, é importante salientar que:

Ser letrado hoje não é garantia de que seremos letrados amanhã, uma vez que as novas tecnologias se renovam continuamente, exigindo leitores e produtores de textos experientes, em várias mídias. As escolas precisam preparar os alunos também para 0 letramento digital, com competências e formas de pensar adicionais ao que antes era previsto para o impresso. (ZACHARIAS, 2016, p. 17).

A exposição da autora vai ao encontro da dimensão individual acerca do uso da tecnologia por parte de alunos, professores e demais sujeitos envolvidos no contexto escolar. Como dissemos, as tecnologias fazem parte do cotidiano dessas pessoas, mas nem sempre em uma perspectiva de ensinoaprendizagem, como se faz necessário atualmente. Vale ressaltar, também, o predomínio da cultura do impresso ainda vigente nas escolas de modo geral. Nesse sentido, a autora considera que a escola precisa incluir uma pedagogia que valorize o universo multimidiático e multissemiótico para além do impresso.

Salientamos, por fim, que essa perspectiva de desenvolvimento de práticas multiletradas na escola perpassa por adequações, sobretudo em relação ao caráter prescritivo e tradicional que permeia orientações curriculares de modo geral. Dessa forma, faz-se necessário discorrer sobre a possiblidade de integração entre currículo e tecnologia, tendo em vista os multiletramentos.

\subsection{A integração entre currículo e TDIC na} agenda dos multiletramentos: a criação de webcurrículos

A consolidação da pedagogia dos multiletramentos, orientada pela inserção de práticas que considerem o enquadramento dos letramentos críticos, conforme os movimentos pedagógicos propostos pelo Grupo Nova Londres (Cf. ROJO, 2012), quais sejam: prática situada, instrução aberta, enquadramento crítico e prática transformada, requerem um olhar mais aguçado para as mudanças necessárias em relação ao currículo, ainda muito pautado no aspecto prescritivo, conforme aponta Almeida (2014), ao tratar da emergência de um webcurrículo.

Sobre essa perspectiva de atuação com base nos multiletramentos, Rojo (2012) aponta dois desafios acerca dessa proposta de ensino: o primeiro traz à tona aspectos relativos à formação, remuneração e 
avaliação dos professores; o segundo, vislumbra uma reflexão no que tange às transformações do currículo e de outras nuances para que tal proposta seja exitosa.

Diante das considerações iniciais desta subseção, é importante refletir sobre a necessidade dessa agenda curricular transformada, tendo em vista a urgência de uso das TDIC para a criação de situações de aprendizagem, diante do isolamento social e do ensino remoto, mais sofrível, sobretudo pela falta de trato com esses dispositivos tecnológicos. Almeida (2014, p. 23-24) já nos oferecia uma visão acerca das contribuições do uso das tecnologias para além do ambiente escolar:

[...] o uso das TDIC na educação, em especial das tecnologias digitais portáteis, representadas por distintos dispositivos tecnológicos com características de mobilidade e conexão à Internet, além de menor custo para aquisição, representa possível abertura para a aprendizagem, o ensino e o desenvolvimento do currículo, que podem se expandir para além dos espaços e tempos delimitados da sala de aula; propiciar a integração da educação formal e da informal com o mundo digital conectado; contribuir com a interlocução entre diferentes culturas e com a formação ao longo da vida.

Com essa visão, a autora discorre sobre a integração possível entre currículo e tecnologias em uma perspectiva interativa. Para ela, essa integração evidencia uma mudança na concepção curricular, pautada em uma prática social pedagógica, mediante - uso das TDIC, com novas possibilidades de flexibilização do currículo, tornando-o instrumento dialógico e validando aspectos culturais, históricos e sociais que lhes são inerentes.

Nesse contexto de integração curriculartecnológica, é que se possibilita a construção de webcurrículos. Nas palavras de Chinaglia e Mendonça (2017), o webcurrículo corresponde a uma construção que possibilita a incorporação de elementos de natureza tradicional, em associação com novos letramentos e com o uso de tecnologias. Com isso, dizem que não se trata apenas da inserção de tecnologias no contexto escolar, mas sim do estímulo ao protagonismo estudantil, mediante o uso de dispositivos tecnológicos.
De acordo com Almeida (2014), há elementos essenciais para a criação de webcurrículos, que são: professor, aluno, TDIC, cultura, proposta curricular, prática pedagógica, investigação científica e resolução de problemas. Nessa composição, ressaltamos o papel do aluno como sujeito ativo da própria aprendizagem e a importância do professor como criador de situações favoráveis à aprendizagem. Salientamos, também, a necessidade de domínio de recursos tecnológicos.

A partir desses elementos, a autora diz que construir webcurrículos significa reconfigurar o papel da escola que, conectada, expande-se para além de seu espaço e de seu tempo, conectando-se, também, com a vida social e com a vida cultural dos sujeitos as quais lhes são inerentes. Ressalta, ainda, a importância de um processo formativo que contemple o professor a respeito das TDIC, considerando as contribuições das tecnologias para o ensino, para a aprendizagem e para a inovação do currículo, possibilitando um processo de transposição didática desse conhecimento para o chão da sala de aula.

Podemos dizer, então, que a criação de webcurrículos consiste em uma pluralização curricular que abarca diversos aspectos, considerando nuances para além da transmissão de informações, realização de atividades prescritivas, entre outras ações descontextualizadas, como apresentam Almeida e Valente (2012). A esse respeito, é importante considerar que:

\begin{abstract}
Em um design de currículo pluralista, culturas e identidades dos aprendizes devem fazer parte da construção do conhecimento. Para isso, é preciso levar em conta três elementos: os modos de aprendizagem, os conteúdos de aprendizagem e o grupo envolvido ou o contexto estabelecido no processo de aprendizagem. (TANZI NETO et al, 2013, p. 137)
\end{abstract}

Com essas considerações acerca das TDIC na perspectiva do ensino, podemos discutir sobre o trabalho com língua portuguesa pautado no uso das tecnologias. Portanto, a seção que segue tem como propósito tratar da visão que se constrói sobre textos, a partir dos recursos tecnológicos para a abordagem de gêneros. 
3 O trabalho com língua portuguesa, multiletramentos e tecnologias na escola

Diante das transformações socioculturais proporcionadas pelos avanços tecnológicos, devemos considerar as novas possibilidades de abordagem sobre os gêneros textuais para o ensino de língua portuguesa. No contexto da tecnologia digital, Marcuschi (2010) apresenta alguns gêneros, erigidos no meio virtual, que são suscetíveis de contemplação no âmbito escolar, como o e-mail, o chat, a videoconferência, entre outros que estão mais evidentes, diante da necessidade de uso das tecnologias para o ensino.

Com o surgimento desses novos gêneros, surgem práticas comunicativas que vão além da visão de texto enquanto artefato impresso, por exemplo. Dessa forma, podemos abarcar outras semioses para a construção de sentidos, pois a "[...] ampliação dos recursos disponíveis para divulgação e troca de informações, por sua vez, propiciou novas formas de construção e socialização do conhecimento: os novos letramentos." (BRAGA, 2013, p; 39 - grifo da autora).

De acordo com a autora, o ensino de língua portuguesa foi direcionado, durante muito tempo, ao desenvolvimento de competências de leitura e de escrita, sem levar em consideração as situações sociais de uso da língua. Para além dessa perspectiva de análise, a ideia sobre gêneros textuais, com o intento de contemplar os eventos de letramento que permeiam as práticas comunicativas dos alunos, pode ser subsidiada pelo que se encontra na internet. Isso, porque há uma seara de textos que pode ser explorada, levando em consideração os conhecimentos prévios dos alunos, bem como inserindo-os em novos processos interativos por meio de gêneros. Nesse sentido, a autora defende que

A produção do aluno pode ir além de um mero exercício escolar, realizado para a leitura do professor e com objetivos de avaliação. Agora o aprendiz tem a possibilidade de publicar seus textos online para leitores virtuais. Nessa situação que envolve o desejo real de interlocução, questões relativas à aceitação linguística do texto (adequações de gêneros), assim como aquelas que afetam a clareza e função dos enunciados produzidos passam a ser mais pertinentes para os aprendizes. (BRAGA, 2013, p. 55).

Ainda com base na autora em tela, as interações entre o uso da internet e as práticas linguísticas cotidianas aproximam-se por conta da multiplicidade de recursos linguísticos que concorrem para a produção de sentidos. Nesse cenário interativo, temos caracterizado os multiletramentos, que correspondem às múltiplas semioses que possibilitam a construção textual de sentidos, indo além do aspecto verbal e contemplando a multiplicidade de culturas (Cf. Rojo, 2012).

Nesse contexto amplo para a abordagem de gêneros textuais, a escola tem relevante função, no sentido de proporcionar o contato com essa diversidade de gêneros que é propiciada pela perspectiva dos multiletramentos. Por isso, as empreitadas no tocante ao ensino de língua portuguesa precisam abarcar essas novas possibilidades de práticas comunicativas as quais, nos dizeres de Marcuschi (2010), já orientam para a reflexão sobre os gêneros emergentes que permeiam os domínios discursivos digitais.

Para que essas possibilidades sejam, de fato, efetivas é importante levar em consideração que esse caminho pedagógico "[...] deve considerar a aprendizagem de leitura e de escrita de textos multimodais que incorporem outras linguagens, sendo que novas práticas de comunicação/interação em diferentes linguagens convocam os multiletramentos.". (TANZI NETO et al, 2013, p. 138).

Apesar da necessidade de abordagens baseadas no uso de recursos tecnológicos para a implementação desses novos letramentos, que emergem nos diversos contextos sociais, devemos considerar que os desafios são inúmeros para a efetivação de práticas pedagógicas na perspectiva tecnológica. Com o isolamento social e com o ensino remoto, evidenciam-se as dificuldades a respeito desse processo. É o que discutiremos na seção iminente. 


\section{0 cenário desafiador para o ensino de} língua portuguesa em tempos de isolamento social

A abordagem com a qual nos ocupamos neste artigo é reflexo da visão que se tem acerca dos desafios em relação à apropriação das tecnologias por parte da escola como um todo, sobretudo em tempos de isolamento social, o que tornou urgente a agenda dos multiletramentos no contexto escolar, bem como a inserção e uso das TDIC para o atendimento dos estudantes que, algumas vezes, não possuem acesso ao universo tecnológico para a aprendizagem, não obstante utilizarem ferramentas dessa natureza para outras finalidades.

Nesse contexto de análise, é importante observar as duas questões centrais que Braga (2013) aponta sobre a abordagem tecnológica da aprendizagem. Primeiro, a autora salienta a dinamicidade proporcionada pelos modos colaborativos de ensino e de aprendizagem por meio do uso da tecnologia. Todavia, a outra questão central trata da ineficácia prática dos recursos tecnológicos como materiais digitais, realização de atividades a distância, bem como o uso das tecnologias em contextos síncronos de sala de aula.

Certamente, essa última questão torna-se mais evidente nesse período de isolamento social, visto que a necessidade súbita de produção de material pedagógico para o atendimento a distância dos estudantes, por meio da utilização de recursos tecnológicos, consiste em algo bastante complexo para os professores que, de modo geral, não possuem habilidades para tal tarefa.

Frise-se, também, como base no que a autora em pauta expõe, que o uso de recursos digitais nem sempre consiste em inovação, pois, muitas vezes, o aparato tecnológico é ferramenta para a reprodução de práticas que se baseiam em perspectivas pedagógicas já recorrentes no cotidiano escolar. Nesse sentido, a autora exemplifica o uso da lousa digital para escrever da mesma forma que se escreve na lousa convencional; ou o uso do powerpoint para resumir aquilo que se poderia resumir no formato impresso, entre outros fatores que demonstram a dificuldade de utilização das tecnologias em uma perspectiva inovadora.

Diante disso, ressalte-se, também, que a condução pedagógica na perspectiva da tecnologia ainda está longe do ideal, pois, quase sempre, é centrada em situações de aprendizagem que não contemplam o uso de ferramentas digitais. Nesse contexto, cabe mencionar a expressão de Braga (2013, p. 46), ao dizer que, em momentos como o que estamos vivendo, de transformação abrupta da realidade educacional, é como se estivéssemos sendo "atropelados pelo bonde da história".

O cenário de transtorno que se criou com a pandemia deve-se, de maneira geral, ao fato de que práticas multiletradas não são predominantes no cotidiano escolar, tendo em vista as limitações inerentes à falta de insumos para o trabalho pedagógico nessa perspectiva, seja no tocante aos recursos físicos, seja pelo fato de os professores, nem sempre, terem uma formação, seja ela inicial ou continuada, que possibilite o desenvolvimento de atividades centradas no uso da tecnologia.

Muitas vezes, há condições para a realização de atividades que possam fomentar o uso das tecnologias, mas não há orientação em relação a esse tipo de prática. Nesse sentido, Braga (2013) aponta para a falta de subsídios nos processos formativos dos professores em relação à condução de atividades pedagógicas que possam ser desenvolvidas com o uso de recursos digitais. Nessa perspectiva, a autora diz que isso é "[...] problemático porque sem uma orientação mais clara o professor deixa de explorar em sua prática recursos oferecidos pelos laboratórios de informática implantados nas escolas." (BRAGA, 2013, p. 47).

Nesse cenário desafiante para o ensino de língua portuguesa na perspectiva digital, podemos mencionar o fato de que as práticas realizadas no contexto escolar não contemplam a diversidade de gêneros que circulam socialmente, ou aqueles com os quais os alunos têm contato em seu cotidiano. Nesse sentido, não se contempla também os gêneros textuais emergentes, como aqueles citados por Marcuschi (2010). Por isso, é importante observar que a "[...] 
fluidez, a dinamicidade e a transitoriedade dos textos digitais requerem, por parte dos professores, proposições didáticas que contribuam para desenvolver, nos alunos, habilidades para lidar com o universo de práticas letradas." (ZACHARIAS, 2016, p. 24).

Um outro desafio a respeito da educação multiletrada ou com viés tecnológico em tempo de isolamento social consiste no fato de que ainda há estudantes que não têm acesso a aparelhos celulares ou à internet. Nesse sentido, diante de uma situação de arranjo social na educação que perpassa pelo uso da tecnologia, há uma problemática muito grande no tocante ao atendimento exitoso desses alunos, por conta do isolamento social. Isso mostra que há necessidade de apropriação tecnológica por parte de professores e alunos.

Essa nova conjuntura que abarca o processo de ensino-aprendizagem com 0 atendimento remoto poderia fortalecer a configuração de novos espaços interativos que, conforme Zacharias (2016), permitem certa autonomia dos alunos no tocante à sua aprendizagem. Apesar disso, parece-nos que o alcance pedagógico de práticas letradas e multiletradas nesse contexto de uso de tecnologias, propostas em função do isolamento social, ainda carece de aprimoramento para atender a uma parcela maior de estudantes de modo mais exitoso. Adiantamos que há uma complexidade acerca desse assunto, que não pode ser exaurida na breve análise a ser apresentada.

\subsection{Uma análise da utilização dos recursos} tecnológicos e o seu aldcance pedagógico: o que dizem os professores?

Diante da discussão proposta, discorreremos sobre um levantamento feito com professores de Língua Portuguesa acerca de aspectos como o uso de recursos tecnológicos neste contexto de pandemia, bem como a eficácia dos instrumentos de aprendizagem utilizados. Trataremos, também, das dificuldades dos alunos e dos próprios docentes para atuarem na modalidade de ensino a distância, que se configurou com o isolamento social. Além disso, observaremos os conteúdos trabalhados e as metodologias utilizadas para tal abordagem, assim como os desafios que os profissionais enfrentam diante dessa situação de atendimento remoto dos alunos.

Como mote para dar conta desses aspectos, elaboramos um questionário que foi respondido por 55 (cinquenta e cinco) professores de escolas da rede estadual de educação do Ceará, da área de Língua Portuguesa, lotados em turmas de ensino médio de uma mesma Coordenadoria Regional de Desenvolvimento da Educação. O questionário, elaborado no Google Docs, foi composto por dez perguntas que tratavam dos aspectos supracitados no primeiro parágrafo desta subseção, e foi enviado aos professores via WhatsApp, mediante a disponibilização de um link de acesso para que os docentes pudessem responder às perguntas propostas.

De forma a preservar a identidade dos professores participantes desta pesquisa, não foi criado campo de identificação para preenchimento no questionário, nem para menção à escola na qual os profissionais trabalhavam. Nessa mesma linha de manutenção do anonimato docente, o link foi disponibilizado para educadores de 15 (quinze) escolas, sem a necessidade de interação entre pesquisadores e professores pesquisados.

Vale dizer, ainda, que a análise realizada teve como ferramenta inicial o questonário respondido pelos professores, mas também baseu-se na experiência docente dos pesquisadores para dar conta de questões que permeiam determinadas condutas docentes e discentes, relatadas por meio das respostas, e que também são responsáveis pelas dificuldades por estes sujeitos.

Assim, seguem os gráficos que ilustram as respostas dos professores: 
Quais recursos tecnológicos, dos listados abaixo, você utiliza para atender aos alunos? (pode haver mais de uma marcação)

55 respostas

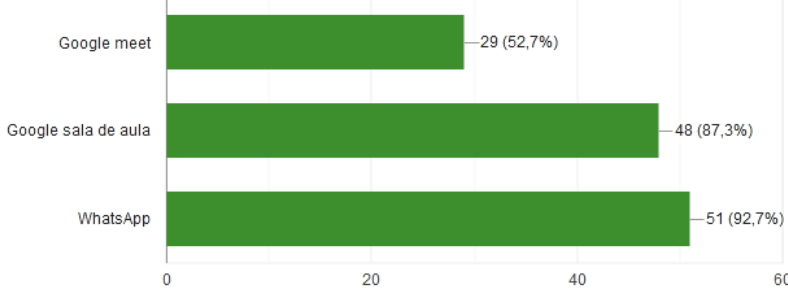

Fonte: Formulário criado no Google Docs

Em relação ao primeiro questionamento, sobre os recursos tecnológicos utilizados, 92,7\% (51 de 55) dos professores utilizam o WhatsApp para atendimento aos alunos, além de utilizarem o Google Sala de Aula e o Google Meet, sendo que este último recurso é utilizado com menor frequência. Provavelmente, o não uso do Meet deve-se à dificuldade de acesso dos alunos e a pouca familiaridade em relação a esses ambientes de aprendizagem, entre outras razões.

Apesar da predileção pelo WhatsApp, a maioria dos professores utilizam os três recursos tecnológicos postos em evidência e os consideram satisfatórios. Vale ressaltar que ambientes como o Google Meet e o Google Sala de Aula oferecem mais recursos para o atendimento dos discentes e, certamente, poderiam ser mais bem aproveitados nas práticas de ensino remoto. Entretanto, com base nas razões expostas sobre as dificuldades de acesso a outros recursos, é importante destacar que o uso de aplicativos multiplataforma como o WhatsApp já faz parte do cotidiano dos estudantes, o que que torna mais viável a utilização desse recurso. Esse cenário vai ao encontro do que Zacharias (2016) aponta sobre a presença das mídias na vida dos alunos as quais, para a autora, não é justo que fiquem de fora dos espaços educativos.

Assim, não obstante a mobilização para o acesso a espaços como o Google Sala de Aula, fomentado pela SEDUC/CE para a realização de atividades pedagógicas, por exemplo, é importante validar a construção de situações de aprendizagem e acompanhamento dos estudantes por meio de alternativas como o WhatsApp, entre outras que sejam do alcance de professores e de alunos, para que o isolamento social não se torne também um período de maior exclusão em relação às situações de aprendizagem.

Gráfico 2 - Participação dos alunos das atividades a distância

De modo geral, como você considera a participação dos alunos nas atividades à distância?

55 respostas

Muito satisfatória

Satisfatória

Pouco satisfatória

Insatisfatória

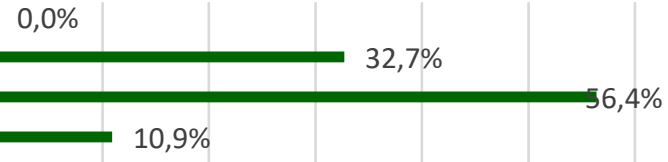

Fonte: Formulário criado no Google Docs

Em relação à participação dos alunos nas atividades a distância, o Gráfico 2 mostra-nos que $56,4 \%$ (31 de 55) dos docentes consideram-na pouco satisfatória. Isso, talvez, esteja além de questões inerentes às dificuldades de acesso a um ou a outro recurso tecnológico, tratando-se mais de uma questão cultural, tendo em vista que, de maneira geral, há o desinteresse a respeito das atividades escolares em situações presenciais de aprendizagem e aqueles alunos que não costumavam fazer suas tarefas na escola, ou em casa, para uma devolutiva na escola, são os mesmos que não fazem as atividades domiciliares, na situação de isolamento social.

Vale mencionar que esse desinteresse envolve diversos fatores, tanto em tempos comuns quanto, principalmente, nesse momento atípico de pandemia, e enumeramos, entre eles, mas sem nos deter, algumas razões colocadas por Silva (2012): pouco ou nenhum recurso tecnológico utilizado para o ensino, ou utilização de forma inadequada, falta de estrutura familiar, desemprego, falta de políticas governamentais.

Ressaltamos, ainda, que nenhuma resposta considerou a participação dos estudantes muito satisfatória. Diante do cenário desafiador apresentado para a educação remota, consideramos que isso está relacionado às dificuldades de adaptação de todos os atores envolvidos nesse processo, pois, com base no que vimos em Braga (2013), essa situação consiste em um atropelamento do processo educacional, em 
função, muitas vezes, da falta de conhecimento técnico para lidar com esse tipo de atendimento aos alunos que, por sua vez, não possuem o letramento tecnológico necessário para a aprendizagem.

Gráfico 3 - Conteúdos abordados no Ensino de Lingua Portuguesa a distância

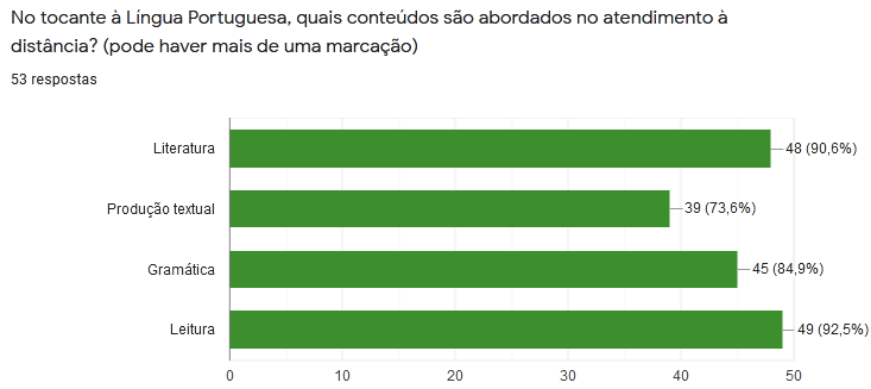

Fonte: Formulário criado no Google Docs

Outros dois questionamentos dizem respeito aos conteúdos abordados com o atendimento remoto e à metodologia utilizada para a exposição das aulas e para a orientação dos alunos acerca dos procedimentos para a realização das atividades. Como se vê, no Gráfico 3, temos os quatro grupos de assuntos inerentes ao ensino de língua portuguesa explorados pelos docentes no ensino remoto. Nele, vemos que há uma distribuição relativamente uniforme dos conteúdos, mas com um percentual em relação à escrita de certa forma inferior às demais abordagens, de $73,6 \%$ (40 de 55) contra um maior percentual voltado para conteúdos que envolvem leitura: 92,5\% (49 de 55), provavelmente, por essa última proposta de atividade mostrar-se mais viável, mas também por ser sempre extremamente necessária para os alunos, em qualquer nível de ensino.

A menor incidência de situações de aprendizagem que fomentem a escrita pode estar relacionada às dificuldades que se encontram com o trabalho de produção textual nas aulas presenciais. Dessa forma, se a produção escrita consiste em um desafio para a prática do cotidiano escolar das aulas presenciais, no ensino a distância isso se torna muito mais evidente, pois os estudantes, em sua maioria, não têm a escrita como um hábito recorrente, nem na escola nem em outro ambiente.
Outra questão que, certamente, dificulta esse trabalho com a escrita, corresponde à maneira como os conteúdos são abordados. Das opções disponibilizadas acerca da exposição dos conteúdos (lives, videoaulas, slides, orientação para a devolutiva de atividades), o que predomina é a orientação de atividades, via WhatsApp, realizada por 96,4\% (53 de 55) dos docentes, conforme podemos observar no Gráfico 4:

Gráfico 4 - Exposição dos conteúdos de Língua Portuguesa

Como ocorre a exposição dos conteúdos? (pode haver mais de uma opção) 55 respostas

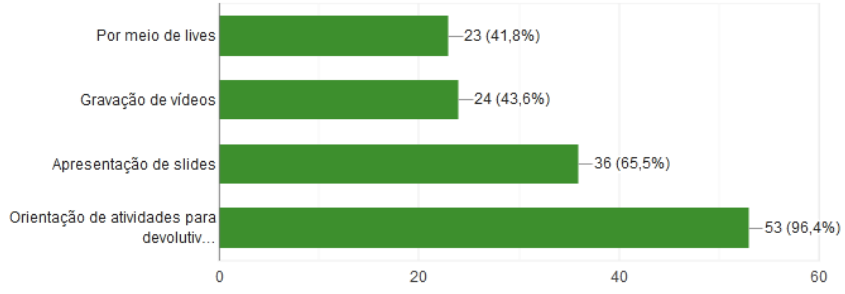

Fonte: Formulário criado no Google Docs

A respeito da orientação de atividades para a devolutiva ocorre, comumente, a exposição de explicações sobre como os alunos devem proceder para realizarem determinada tarefa, retirada do livro didático, baseada em vídeos enviados aos alunos, entre outras exposições. Salientamos que esse tipo de condução metodológica da aprendizagem é mais recorrente na interação via WhatsApp e no Google Sala de Aula, tendo em vista o caráter predominantemente assíncrono desses recursos em relação ao Meet, por exemplo.

Já no que se refere às dificuldades de professores e de alunos acerca do contexto de educação a distância, apontam-se os desafios de adequação à nova rotina de trabalho, por parte dos professores, e a ausência de uma rotina de estudos dos discentes. No entendimento dos docentes, o grande problema dos alunos, como vemos no Gráfico 5 , consiste na falta de uma rotina de estudos para darem conta das atividades propostas no ensino remoto, conforme resposta de $85,5 \%$ (47 de 55) dos professores. Consideramos que essa dificuldade pode ser associada à falta de acompanhamento familiar, pois isso figura entre um dos problemas recorrentes 
em relação ao ensino convencional, se considerarmos que as influências familiares podem ser determinantes para a definição do comportamento dos alunos (FRANKIV; DOMINGUES, 2016). Contudo, certamente há outras causas consideráveis que comprometem uma rotina de estudos.

Entretanto, apesar da ausência de rotina de estudos dos alunos, é necessário destacar a falta de acesso à internet, que é apontada como a segunda maior dificuldade dos discentes. Esse tipo de problema evidencia outros, de natureza social, que assolam o nosso alunado, como a falta de infraestrutura nos lares desses alunos para a realização de suas tarefas escolares, pois, além de acesso à internet, faltam outros insumos que interferem no processo de aprendizagem nesse contexto de ensino remoto.

Gráfico 5 - Visão dos professores acerca das dificuldades dos alunos no ensino a distância.

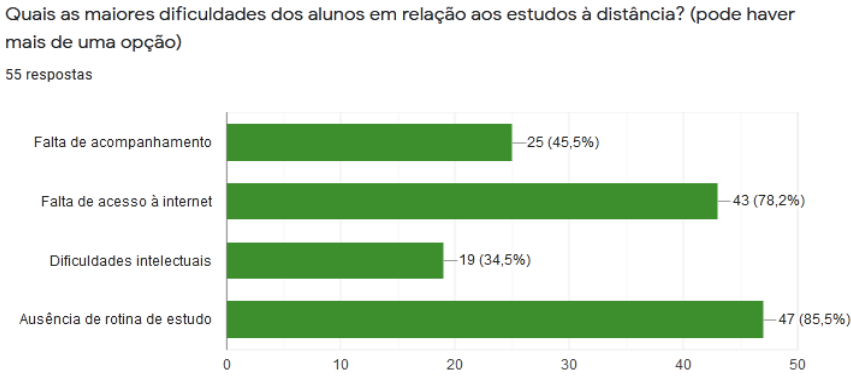

Fonte: Formulário criado no Google Docs

Em relação às dificuldades apontadas pelos professores acerca de sua atuação no ensino remoto, evidencia-se como problema a adequação à nova rotina de estudo, além da falta de formação específica como uma dificuldade para o uso das tecnologias na perspectiva do ensino, de acordo com o que se apresenta no Gráfico 6:

Gráfico 6 - Dificuldades dos professores para atendimento aos alunos

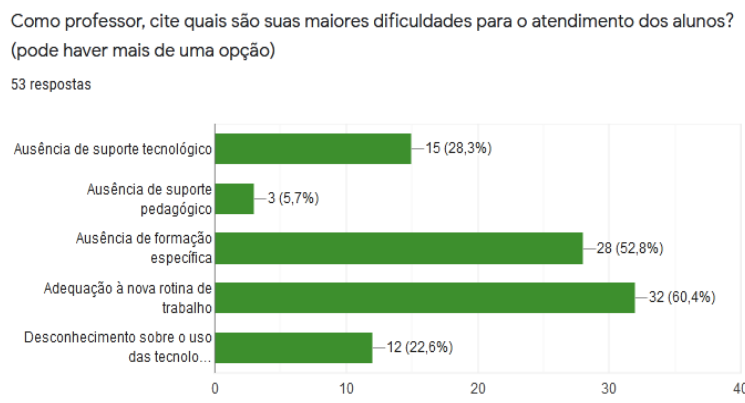

Dos dados apresentados no Gráfico 6, destacamos as dificuldades acerca da ausência de formação específica dos professores (52,8\%; 28 de $55)$, visto que coadunam com os desafios apresentados por Rojo (2012) sobre a necessidade de formação docente para a atuação em uma perspectiva de abordagem pautada em eventos de letramentos críticos e de multiletramentos, levando em consideração o uso de dispositivos tecnológicos.

Podemos associar esses resultados destacados do Gráfico 6, ainda, ao que Braga (2013) diz sobre as dificuldades de utilização de dispositivos tecnológicos, mesmo que o acesso seja pleno, tendo em vista que há, o mais das vezes, uma metodologia tradicional que perpassa o uso da tecnologia.

No entanto, ainda há um maior percentual de respostas que apontam para dificuldades de adequação à nova rotina de trabalho, 60,4\% (32 de 55). Isso provavelmente se deve às diversas mudanças condicionadas pelo isolamento social, visto que a maioria das pessoas está trabalhando de casa, de modo que as famílias tiveram mudanças de rotina tanto em seus respectivos trabalhos quanto na educação e no ensino dos filhos, na reorganização das tarefas diárias como um todo.

Para finalizarmos o questionário, perguntamos sobre os maiores desafios para o atendimento remoto. Sobre isso, o desafio apontado pelos professores foi a falta de interesse dos alunos, apresentando uma porcentagem de $87,3 \%$ (48 de 55). Destaca-se, também, a criação de situações para a aprendizagem e a avaliação da participação dos discentes em relação ao que lhes é proposto no cotidiano, por meio dos recursos de que dispõem os professores: 58,2\% (32 de 55). Essa dificuldade de pensar em diferentes situações de aprendizado e em novas formas de avaliar ratifica as dificuldades da maioria dos docentes para lidar com esse contexto totalmente novo e com outros que possam surgir, bem como confirma a necessidade de formações e capacitações nessa direção, que abranjam, principalmente, o conhecimento e o aproveitamento de ferramentas do universo tecnológico. 
Gráfico 7 - Desafios encontrados no contexto da educação a distância

Quais os desafios enfrentados nesse contexto de educação à distância? (pode haver mais de uma opção)

55 respostas

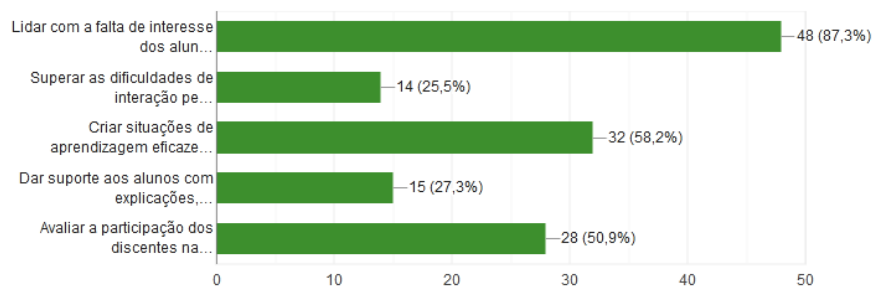

Fonte: Formulário criado no Google Drive

Diante dessa breve análise, salientamos 0 importante papel do professor para otimizar as ações inerentes ao ensino remoto, predominantemente pautado no uso de recursos tecnológicos. Entretanto, há desafios para a transformação curricular, conforme já apontava Rojo (2012) e para a criação de webcurrículos que vão além do trabalho do professor.

No tocante à língua portuguesa, percebemos que as dificuldades para o desenvolvimento das atividades relativas à disciplina correspondem àquelas que interferem nas disciplinas de maneira geral e à menor frequência de trabalho com escrita reflete o que ocorre nas aulas presenciais, tendo em vista as dificuldades dos alunos, no que tange à produção de textos.

De modo geral, observamos a necessidade da compilação de esforços dos atores educacionais para que o ensino remoto tenha eficácia, pois esse cenário é desafiador para professores, alunos, pais, gestores escolares e governantes. Para o ensino de língua portuguesa, emerge a importância de práticas multiletradas e o uso das TDIC.

\section{Considerações finais}

No contexto pandêmico no qual nos encontramos, reconfigurações diversas foram necessárias para a adequação ao isolamento social. No âmbito educacional, isso não é diferente, pois o ensino remoto consiste em uma nova configuração das situações de aprendizagem desenvolvidas pelas escolas.
$\mathrm{Da}$ análise quantitativa, observamos os seguintes resultados: 92,7\%, equivalentes a 51 dos 55 professores questionados, usam WhatsApp para atendimento aos alunos; $56,4 \%$, correspondentes a 31 dos 55 docentes, consideram a participação dos alunos pouco satisfatória; $92,5 \%$, referentes a 49 de 55 pesquisados, abordam conteúdos relacionados à leitura; $96,4 \%$, que equivalem a 53 dos 55 professores indagados, usam WhatsApp para a orientação de atividades; $85,5 \%$, que correspondem a 47 dos 55 docentes questionados, entendem que a maior dificuldade dos alunos é a rotina de estudos; $60,4 \%$, que se referem a 32 dos 55 participantes da pesquisa, afirmam ter dificuldades de adequação à nova rotina de trabalho; e, $87,3 \%$ equivalentes a 48 dos 55 professores, consideram que 0 maior desafio enfrentado no contexto da educação a distância é lidar com a falta de interesse dos alunos.

No tocante à língua portuguesa, observamos que as práticas de ensino, pautadas em sua maioria na orientação de atividades para devolutiva dos alunos, principalmente com base no livro didático, consistem em uma transposição daquilo que se faz tradicionalmente no contexto de ensino presencial. Dessa forma, o uso da tecnologia não é feito com vistas à exploração do potencial do universo tecnológico, sendo um mero caminho que leva a práticas pedagógicas inerentes à cultura do impresso.

A investigação mostrou que a pouca exploração dos recursos tecnológicos, a participação pouco satisfatória dos alunos, a falta de diversificação de conteúdos expostos e do modo de exposição, a inexistência de uma rotina de estudos e o desinteresse de maior parte do alunado constituem o retrato do contexto atual da educação a distância neste momento de isolamento social, na realidade dos professores participantes da pesquisa.

Assim, a discussão nos revela, sobretudo, que mais do que nunca, há urgência de aprimoramento do uso das tecnologias na perspectiva do ensino. Isso pode acontecer a partir do estímulo para 0 desenvolvimento de práticas multiletradas e estruturação dos ambientes digitais de aprendizagem com a possibilidade de acesso integral de todos os 
alunos e com a criação de atividades que permitam a interação por meio da tecnologia, além da formação docente para uma atuação mais exitosa.

\section{REFERÊNCIAS}

ALMEIDA, M. E. B. Integração, currículo e tecnologias: concepção e possibilidades de criação de web currículo. In: ALMEIDA, M. E. B.; ALVES, D. R. M.; LEMOS, S. D. V. (org.). Web currículo: aprendizagem, pesquisa e conhecimento com uso de tecnologias digitais. Rio de Janeiro: Letra Capital, 2014. Disponível em:

https://issuu.com/letracapital/docs/webcurrículo. Acesso: 11 jun. 2020.

ALMEIDA, M. E. B.; VALENTE, J. A. Integração, currículo e tecnologias e a produção de narrativas digitais. Currículo sem fronteiras, v. 12, n. 3, p. 57/82, set./dez. 2012. Disponível em:

http://www.curriculosemfronteiras.org/vol12iss3article s/almeida-valente.pdf. Acesso em: 11 jun. 2020.

BRAGA, D. B. Ambientes digitais: reflexões teóricas e práticas. São Paulo: Cortez, 2013.

CHINAGLIA, J. V.; MENDONÇA, M. Materiais didáticos para os novos e multiletramentos: uma proposta de atividade gamificada. Linguagem em Foco, UECE, v. 9, n. 1, 2017. Disponível em: https://revistas.uece.br/index.php/linguagememfoco/ar ticle/view/1533 Acesso em: 10 jun. 2020.

FRANKIV, M. A.; DOMINGUES, S. C. Desinteresse e proposições para escola atual: contribuições do pensamento complexo. Revista Tempos e Espaços em Educação, São Cristóvão, v. 9, n. 19, p. 113-128, 2016.

MARCUSCHI, L. A. Gêneros textuais emergentes no contexto da tecnologia digital. In: MARCUSCHI, L. A.; XAVIER, A. C. (org.). Hipertexto e gêneros digitais: novas formas de construção de sentido. 3. ed. São Paulo: Cortez, 2010.

PRODANOV, C. C; FREITAS, E. C. de. Metodologia do trabalho científico: métodos e técnicas da pesquisa e do trabalho acadêmico. 2 ed. Novo Hamburgo:

Feevale, 2013

ROJO, R. H. R. Pedagogia dos multiletramentos: diversidade cultural e de linguagens na escola. In: ROJO, R. H. R.; MOURA, E. (org.). Multiletramentos na escola. São Paulo: Parábola Editorial, 2012.

SILVA, D. N. da. A Desmotivação do Professor em Sala de Aula nas Escolas Públicas do Município de São José dos Campos - SP. 2012. 52 f. Monografia
(Especialização em Gestão Pública Municipal) Educação a distância - Universidade Tecnológica Federal do Paraná, Curitiba, 2012.

SOARES, M. Letramento: um tema em três gêneros. 3. ed. Belo Horizonte: Autêntica Editora, 2014.

STREET, B. Letramentos sociais: abordagens críticas do letramento no desenvolvimento, na etnografia e na educação. São Paulo: Parábola Editorial, 2014.

TANZI NETO, A. et al. Multiletramentos em ambientes educacionais. In: ROJO, R. Escola conectada: os multiletramentos e as TICs. São Paulo: Parábola, 2013.

ZACHARIAS, V. R. de C. Letramento digital: desafios e possibilidades para o ensino. In: COSCARELLI, C. V. (org.). Tecnologias para aprender. São Paulo: Parábola Editorial, 2016.

SOUZA, Wellington Gomes de; BEZERRA, Jaqueline de Jesus. A pandemia e a urgência das tecnologias: reflexões sobre os desafios para o ensino de língua portuguesa em tempos de isolamento social. Signo, Santa Cruz do Sul, v. 46, n. 85, p. 2-14, jan. 2021. ISSN 1982-2014. Disponível em: <https://online.unisc.br/seer/index.php/signo/article/view/156 26>. doi:https://doi.org/10.17058/signo.v46i85.15626. 